\title{
Factors associated with health-related quality of life among Chinese caregivers of the older adults living in the community: a cross-sectional study
}

\author{
Xiaoshi Yang, Yiming Hao, Shernelle Marlah George and Lie Wang*
}

\begin{abstract}
Background: Under the culture of filial piety and due to the Confucianism spirit in China, family caregivers usually undertake the responsibilities of caring for the older adults. They usually suffer from a heavy burden which is believed to impair their mental and physical health. Thus this study aims to describe the health-related quality of life (HRQOL) among Chinese caregivers of the older adults living in the community and explore the predictors of caregivers' HRQOL.

Methods: A cross-sectional study was conducted through convenience sampling. The study population was composed of 1,144 caregivers of older adults who suffered from one or more types of chronic diseases in 15 communities in 3 eastern cities of China. Family caregivers were interviewed face-to-face using the 36-item ShortForm Health Survey (SF-36) and the ZARIT Caregiver Burden interview (ZBI) scales. The Antonovsky's Sense of coherence (SOC) scale was also used to measure personal coping capability of the caregivers. Hierarchical multiple regression analysis (HMR) was performed to explore the predictors of caregivers' HRQOL.

Results: The majority of the caregivers were females (60.0\%) or adult children (66.5\%). Mental QOL was significantly lower than physical QOL. Hierarchical multiple regression analysis showed that Demographic Characteristics of Caregivers, Patients' Characteristics, and Subjective Caregiver Burden explained most of the total variance of all aspects of HRQOL. While, Objective Caregiving Tasks was only associated with physical QOL. Subjective Caregiver Burden was the strongest predictor of both physical and mental QOL. SOC was also a strong predictor of physical and mental QOL.

Conclusions: The mental QOL of the caregivers of older adults was disrupted more seriously than physical QOL. Additionally, Subjective Caregiver Burden might decrease caregiver' health. A decrease in caregiver burden could promote better management of caregiving tasks, and improve HRQOL. Also, coping capabilities, like SOC, are needed to decrease the impact of caregiving on HRQOL of Chinese caregivers of the older adults.
\end{abstract}

Keywords: Older adults, Subjective caregiver burden, Sense of coherence, HRQOL

\section{Background}

In recent times, China's concern about the national burden placed on the country by the elderly has heightened. The population of the elderly in China has been aging dramatically, and the number of Chinese people aged 60 and over will increase to 400 million by the year 2050 , accounting for $25 \%$ of the whole population [1].

\footnotetext{
* Correspondence: liewang@mail.cmu.edu.cn

Department of Social Medicine, School of public health, China medical university, No.92 North second road, Heping District, Shenyang 110001, China
}

Advances in healthcare and nutrition, combined with the one child policy, have led to a small family size, the increase of empty-nest families as well as elderly people living alone. These have caused a corresponding rise of the elderly dependency ratio. The result is a population bulge called the "4-2-1" phenomenon, in which one child is supporting two parents and four grandparents. Older adults are at a high risk for chronic diseases. Once the disease occurs, the high cost of care is overwhelming for many families, which could result in great financial and caregiving burden. Owing to the paucity of formal 
institutional methods for long-term care, and due to the culture of filial piety and the Confucianism spirit in China, family members are usually left with the responsibilities of caring for the elderly.

Caring for the elderly not only affects caregivers' daily lives, but also poses dramatic and considerable psychological and physical challenges. The negative effects of such strain affect their present and future daily life and health. Caregiving requires much time and effort, great material and emotional expenditure, and also hinders caregivers' social engagements. The role of caregiving can be highly stressful, burdensome, and hence, compromises the caregiver's quality of life, which could lead to considerable physical, psychological and social impairments [2]. Research has consistently reported that increased caregiver burden was associated with a decline of well-being and quality of life in many countries $[3,4]$. Schulz found that caregivers who were providing care and experiencing caregiver burden and strain had a $63 \%$ higher risk of mortality than non-caregivers [5]. This, in more cases than expected, exceeds that of the elderly themselves. Numerous studies have also shown that caregivers have a higher risk of both physical and mental health problems, as compared to non-caregivers [6-8]. Caregivers are usually the hidden victim of the disease, and so have been labeled the "hidden patients" [9].

Sense of Coherence (SOC) during the process of caregiving has yielded various findings as to caregivers' health. Sense of coherence is the ability of caregivers to mobilize their coping resources during periods of caregiving [10,11]. Antonovsky [12] found that people with a stronger SOC despite extremely pressing circumstances such as providing caregiving to their family members could positively deal with stress and protect health. Caregivers with a strong SOC, which refers to their ability to respond to stressors by the appropriate use of adaptive coping resources, can avoid breakdown, alleviate mental health problems and promote physical health.

The effects of caring for older adults on caregiver's health have moved to the forefront nowadays in Western countries, Japan and Taiwan. However, very little is known about caregivers of older adults in mainland China. Thus, this study aims to describe the quality of life (QOL) among Chinese caregivers of older adults and explore the predictors of caregivers' QOL. Information derived from this study may provide evidence for policymakers to attenuate caregiver burden, promote quality of life and well-being among caregivers.

\section{Methods}

\section{Study design and sample}

A cross-sectional study was conducted from November 2010 to August 2011. The sample used in this study consisted of 1,500 caregivers of the older adults living in the community. A convenience sample of primary family caregivers of the elderly with one or more types of chronic diseases was selected from 15 communities in 3 eastern cities of China (Shenyang of Liaoning Province, Yantai of Shangdong Province and Nanqiao of Shanghai). All cities contain a large percent of the elderly population, locating at the north, central and south of eastern China. Primary family caregivers of ages 18 years and older, who had cared for the elderly with the ages of 60 years and older, for at least the past 6 months, were enrolled in this study. This time frame was chosen based on the criteria for the period of long-term care for older adults [13,14].

Family doctors from the community service centres who were participating in the project identified the individuals who met the criteria and explained the study to them and their primary family caregivers. If the caregivers agreed to participate, they were asked to sign consent forms and enrolled in the study. All the participants were well-informed about the content and aim of the study. After obtaining the written informed consent about the conduct of the survey, caregivers were interviewed face-to-face by doctors or trained surveyors in the home of the elderly. The procedures followed were in accordance with and approved by, the ethical standards of the Committee on Human Experimentation of China Medical University.

Of the 1,500 caregivers identified, 210 declined to participate resulting in an $86.0 \%$ consent rate. Eighty-five were excluded because they dropped out of the study, and sixty-one were excluded because of missing values exceeding $10 \%$ in the questionnaire. The characteristics (Sex, Race, and Objective Caregiving Loads) of the remaining 1,144 caregivers included in the analysis were similar to those of the 150 caregivers who were excluded.

\section{Caregivers' quality of life Assessment of QOL}

The 36-item Short-Form Health Survey (SF-36) [15,16] was applied to assess QOL of caregivers. The SF-36 consists of 36 items that measures eight different dimensions of health: physical function, role limitations related to physical problems, bodily pain, general health perception, vitality, social functioning, role limitations due to emotional problems and mental health. These dimensions can be categorized into physical component summary (PCS) and mental component summary (MCS). The health concepts are described by a range in score from 0 to 100 , with higher scores indicating better health. The internal consistency of the questionnaire was Cronbach's $\alpha=0.81$ in this study.

\section{Independent variables}

Demographic Characteristics of Caregivers

Demographic Characteristics of Caregivers included age, gender, education level (<senior middle school/ $\geq$ senior 
middle school), marital status (married/other), currently employed (yes/no), financial status, number of caregivers, and relationship to the patient. Family caregivers were asked whether they suffered from any chronic disease. 'Chronic disease' was defined as 'yes' if any common chronic disease (e.g., hypertension, cardiovascular disease, diabetes, and arthritis) had ever been diagnosed.

\section{Characteristics of the Elderly}

These questionnaires were completed by the caregivers through structured face to face interviews conducted by the doctors and trained interviewers. The doctors and interviewers acquired information on gender, age, education level, marital status (married/other), income level, functional status, and number of chronic diseases. Functional status was measured by the Activities of Daily Living Scale (ADL) designed by Lawton and Brody in 1969 [17]. ADL, consisting of 14 items, measures the degree of independence in basic (e.g., dressing and grooming) and instrumental (e.g., medication and financial management) daily activities. Each item is scored on a 4-point scale, reflecting independence, the need for little assistance, the need for much assistance or dependence. Total scores range from 0 to 42 , with higher scores reflecting higher levels of dependency.

\section{Objective Caregiving Loads}

Objective Caregiving Loads measured in this study included care tasks, level of care, and the amount of time spent in providing care each day. Care tasks and level of care were measured by the amount of assistance provided in personal care, homemaking, transportation, and health care, as determined by Emanuel et al. [18]. Family caregivers were asked to rate the amount of assistance they provided to the patients in each of these four categories on a four-point scale ranging from "none at all" to "a lot". Each item has four response categories: $0=$ none at all, $1=$ sometimes, $2=$ frequently and $3=$ always. A composite score for the total assistance provided was computed by summing the scores of those four items (Cronbach's alpha $=0.91$ ). The number of caregivers refers to the total number of the caregivers who provide care to the elderly including primary and secondary family caregivers. The amount of time spent each day in caregiving was classified into less than or equal to 4, 56, 7-8, and 9-24 hrs/day. Care duration was classified into less than or equal to1, 1-4 and more than 4 years.

\section{Subjective Caregiver Burden}

Subjective Caregiver Burden was measured with The Zarit Caregiver Burden Interview (ZBI) [19], which was developed by Zarit in 1985. It is composed of 22 items graded on a scale from 0 to 4 , according to the presence or intensity of an affirmative response. The questions refer to the caregiver/patient relationship and evaluate the caregiver's physical health, psychological well-being, finances, and social life. Each item has five response categories: $0=$ none at all, $1=$ occasionally, $2=$ =sometimes, $3=$ frequently and $4=$ always. Caregiver burden is evaluated by means of the total score obtained from the sum of the questions. The total score ranged from 0 to 88 , with higher scores indicating a heavier caregiver burden. The Chinese version of ZBI had been established [20] in previous studies and had a higher reliability and validity. The reliability of this study was 0.85 .

\section{Personal Coping Capability}

The Chinese edition of the Antonovsky's Sense of coherence (SOC) scale [12] was used to measure personal coping capability. It consists of 13 items, including three critical attributes within the SOC construct: meaningfulness, comprehensibility, and manageability. Respondents were asked to rate themselves on a seven-point Likert scale. The total score ranged from 13 to 91, with higher scores indicating a stronger SOC. The Cronbach's alphas of the SOC scale from published studies ranged from 0.70-0.92 for various samples [21]. The Cronbach's alpha coefficient was 0.83 for SOC in this study.

\section{Statistical analysis}

The distributions of QOL in categorical variables were evaluated using t-test and one-way analysis of variance (ANOVA). Correlations between QOL and continuous variables were examined by Pearson's correlation. If the correlation between two variables was more than 0.5 , these variables were regarded as co-line variables, and were adjusted in the multivariate analysis. In this study, no co-line variables were found. Hierarchical Multiple Regression (HMR) analysis was conducted to test the incremental variance by any given set of independent variables. The QOL scores were used as dependent variables. The independent variables were entered in the following steps: Step 1: characteristics of the elderly; Step 2: demographic characteristics of the caregivers; Step 3: objective caregiving loads; Step 4: subjective caregiver burden and; Step 5: sense of coherence. The analysis proceeded in stages by successively including several blocks of independent variables in the regression model. Blocks of variables entered in later stages were thus tested for their extra contribution after the contributions of earlierentered variables had been removed. The relative importance of the variables retained in the final multiple regression models contributed to the explained variance of the QOL, which was represented as the standardized $\beta$ [22]. Fit of the model was assessed using the $\mathrm{R}^{2}$-value. Statistical analysis was performed using the Statistical Package for Social Science Version 11.5. A two-tailed probability 
value of less than 0.05 was considered to indicate statistical significance.

\section{Result}

\section{Description of the characteristics of the caregivers and} the elderly

The 1144 caregivers who completed the questionnaires effectively constituted a valid response rate of $76.3 \%$. The basic characteristics of the participants are provided in Table 1. The average age of the older adults was $72.1 \pm 8.7$ years old. There were 630 (55.1\%) males and 514 (44.9\%) females. The older adults' chronic diseases categories in this study were stroke (184), arthritis (246), cervical spondylosis (157), hypertension (498), coronary heart disease (243), diabetes (240) and cancer (67). The older adults with an educational level of higher than junior middle school accounted for more than 52.4\%. Approximately $57.0 \%$ of the older adults are married, and their mean ADL scale was 26.2, SD 12.7.

Caregivers' average age was $44.3 \pm 11.5$ years old, ranging from 20-79 years old. They consisted of 460 (40.0\%) males and 684 (60.0\%) females. In these subjects, the majority of the caregivers were adult children (66.5\%). The percentage of currently employed caregivers was $68.9 \%$. Nearly half of the family caregivers sometimes provided assistance to the elderly in personal care, homemaking, transportation, and health. The median of care duration for patient was 2.5 years, ranging from half a year to 32 years. More than one third (34.2\%) of the caregivers spent 5-6 hours in caregiving each day. The mean ZBI scale was 27.3, SD 15.0. However, caregivers reported that caregiving created substantial positive effects like SOC in caregiving. The strength of SOC $(56.1 \pm 5.6)$ in caregivers was moderately strong, which was equal to the level of SOC in cancer caregivers in Taiwan (59.8 \pm 15.9$)$ [23].

\section{Description of the caregivers' QOL}

In this study, the caregivers of older adults suffered lower levels of PCS and MCS, which was much lower than the levels of general mainland Chinese adults and the Chinese caregivers of the elderly in Hong Kong $[24,25]$; but higher than the caregivers of stroke patients [26]. The mean scores of caregivers' QOL based on the demographic characteristics of caregivers and objective caring tasks are listed in Table 2. Mental QOL was significantly lower than psychical QOL. Female caregivers exerted a significantly lower level of MCS than the male caregivers. Caregivers with an education level of senior middle school or above displayed a higher degree of both PCS and MCS, while caregivers suffering from chronic disease tended to reported severer physical and mental QOL. Caregivers with lower monthly household income tended to exerted lower PCS and MCS. Spousal caregivers suffered lower levels of physical and mental QOL than those of other familial relationships to the older adult. Caregivers providing care to an ill family member, who suffered from more than one type of chronic disease, had QOL scores lower than those caring for the elderly with one chronic disease. Differences in age of caregivers, whether or not they were living together with the elderly, as well as care duration were not statistically significant. Family caregivers who cared for the elderly with higher levels of dependency (ADL scores), experienced a significantly lower level of physical and mental QOL.

\section{The predictors of caregivers' QOL}

Tables 3 and 4 shows the final results of the hierarchical multiple regression models of caregivers' QOL. The total of $25.5 \%$ and $28.2 \%$ of variance were explained by the final regression model in PCS and MCS respectively. Results from the $\mathrm{R}^{2}$ change indicated that Subjective Caregiver Burden contributed most to the variance of both PCS and MCS. It also indicated that the demographic characteristics of the caregivers was the second highest contributor to the variance of PCS and MCS. Each block of independent variables made a significant contribution to the variance of caregivers' physical QOL. With the exception of objective caregiving tasks ( $\mathrm{P}$ values in all variables of objective caregiving tasks were higher than 0.05), every block of the independent variables made a significant contribution to the variance of MCS. Subjective Caregiver Burden was the strongest predictor of all aspects of QOL, whereas SOC was positively associated with PCS and MCS.

\section{Discussion}

The results from this study indicate that most Chinese caregivers of the elderly suffer from impaired QOL. This was much lower than the QOL levels of the general mainland Chinese adults, and the Chinese caregivers for the elderly in Hong Kong [24,25]; but higher than the caregivers of stroke patients [26]. And this was consistent with Saunders' study which found that the caregivers of the heart failure patients felt their health had worsened because of caregiving [27]. Moreover, mental QOL of the caregivers was disrupted more seriously than physical QOL.

In this study, Subjective Caregiver Burden was the strongest predictor of both PCS and MCS. Both physical and mental QOL of caregivers were best predicted by Subjective Caregiver Burden and the Demographic Characteristics of Caregivers. In addition, caregivers' mental QOL was also predicted by the patients' characteristics. These findings suggested that not only the objective aspects of caregiving, but also subjective caregiver burden were associated with caregivers' QOL. Caregiving has disproportionate burdensome effects on 
Table 1 Demographic characteristics of caregivers and the older adults

\begin{tabular}{|c|c|c|c|c|c|}
\hline Variables & $\mathbf{N}$ & $\%$ & Variables & $\mathbf{N}$ & $\%$ \\
\hline Caregivers' demographic characteristics & & & The elderly' characteristics & & \\
\hline Gender & & & Gender & & \\
\hline Male & 460 & 40.21 & Male & 630 & 55.07 \\
\hline Female & 684 & 59.79 & Female & 514 & 44.93 \\
\hline Age (years old) & & & Age (years old) & & \\
\hline$\leq 40$ & 444 & 38.81 & $60-69$ & 453 & 39.6 \\
\hline $41-49$ & 391 & 34.18 & $70-79$ & 438 & 38.3 \\
\hline$\geq 50$ & 309 & 27.01 & $\geq 80$ & 253 & 22.12 \\
\hline Marital status & & & Marital status & & \\
\hline Married & 995 & 86.98 & Married & 652 & 56.99 \\
\hline Others & 149 & 13.02 & Others & 492 & 43.01 \\
\hline Educational level & & & Educational level & & \\
\hline$<$ Senior middle school & 512 & 44.76 & $<$ Junior middle school & 545 & 47.64 \\
\hline$\geq$ Senior middle school & 632 & 55.24 & $\geq$ Junior middle school & 599 & 52.36 \\
\hline Monthly household income of caregivers(Yuan) & & & Income level of the elderly(Yuan) & & \\
\hline$<1000$ & 160 & 13.99 & $<1000$ 元 & 342 & 29.90 \\
\hline 1000-1999 & 291 & 25.44 & 1000-1999 & 305 & 26.66 \\
\hline 2000-2999 & 339 & 29.63 & 2000-2999 & 315 & 27.53 \\
\hline$\geq 3000$ & 352 & 30.77 & $\geq 3000$ & 182 & 15.91 \\
\hline Chronic diseases & & & Number of chronic diseases & & \\
\hline No & 413 & 36.10 & 1.00 & 638 & 55.77 \\
\hline Yes & 731 & 63.90 & 2.00 & 281 & 24.56 \\
\hline Living with the elderly & & & $\geq 3.00$ & 225 & 19.67 \\
\hline Yes & 534 & 46.68 & Caregiving in assistance for daily living & & \\
\hline No & 561 & 49.04 & Not at all & 215 & 18.79 \\
\hline Missing & 49 & 4.28 & Occasionally & 537 & 46.94 \\
\hline Relationship to the patient & & & Frequently & 244 & 21.33 \\
\hline Spouse & 111 & 9.70 & Always & 148 & 12.94 \\
\hline Daughter & 330 & 28.85 & Caregiving in assistance for housekeeping & & \\
\hline Son & 318 & 27.80 & Not at all & 138 & 12.06 \\
\hline Daughter in law & 113 & 9.88 & Occasionally & 501 & 43.79 \\
\hline Others & 272 & 23.78 & Frequently & 311 & 27.19 \\
\hline Numbers of caregivers & & & Always & 194 & 16.96 \\
\hline 1 & 215 & 18.79 & Caregiving in assistance for transportation & & \\
\hline 2 & 369 & 32.26 & Not at all & 180 & 15.73 \\
\hline 3 & 249 & 21.77 & Occasionally & 481 & 42.05 \\
\hline$\geq 4$ & 264 & 23.08 & Frequently & 264 & 23.08 \\
\hline Missing & 47 & 4.11 & Always & 204 & 17.83 \\
\hline Currently employed & & & Not at all & 15 & 1.31 \\
\hline no & 330 & 28.85 & Caregiving in assistance for health care & & \\
\hline yes & 788 & 68.88 & Not at all & 188 & 16.43 \\
\hline Missing & 26 & 2.27 & Occasionally & 502 & 43.88 \\
\hline
\end{tabular}


Table 1 Demographic characteristics of caregivers and the older adults (Continued)

\begin{tabular}{lllll}
\hline Time spent in caregiving everyday & & & Frequently & 282 \\
$<4 \mathrm{~h}$ & 308 & 26.92 & Always & 17.65 \\
$5-6 \mathrm{~h}$ & 391 & 34.18 & & 172 \\
$7-8 \mathrm{~h}$ & 196 & 17.13 & \\
$9-24 \mathrm{~h}$ & 249 & 21.77 & \\
Care duration (years) & & & \\
$\leq 1$ & 317 & 27.71 & \\
$1-4$ & 417 & 36.45 & \\
$\geq 4$ & 410 & 35.84 & & \\
\hline
\end{tabular}

all aspects of QOL. Additionally, individual personal coping capability like SOC played a positive role in alleviating burden and could optimize QOL. This is in support with previous studies $[23,28]$ that positive beliefs influence the appraisal of stressful situations and so, could promote health and well being.

In this study we found that the functional dependency of the elderly had significant impacts on the caregivers' physical health. Our finding is consistent with the existing literature that patients' functional state was significantly related to caregivers' psychosocial burden and was linked to caregiver's QOL [29,30]. This takes the results of existing literature further in showing that caring for the elderly with low daily living abilities, is associated with caregivers' poor physical QOL. Caregiving in assistance for daily living, housekeeping, transportation and health care, time spent in caregiving everyday and care duration in the block 3 of objective caregiving loads were not associated with PCS, while the number of caregivers was the predictors of PCS. Caregivers caring for the elderly with high functional dependency engaged in more physical expenditure, which usually led to lack of physical vigor and strength. Therefore, the degree of dependency for assistance of daily living can well predict physical well being of caregivers. Further interventions to improve caregivers' QOL should target at improving poorer functioning of the elderly.

Currently in China there are no community services or long-term care services for neither the elderly nor chronically ill patients, which makes it difficult for older adults and their families to afford expensive medical treatment and care tasks. Sometimes caregivers had to stop working in order to give full-time care to the elderly. In the present study, we found that nearly $30 \%$ of the caregivers only took care of the elderly, they are more likely to spend more time taking care, experiencing physical conflicts of caring tasks, which may be the cause of poor physical health. Lower household income and loss of employment due to caregiving added to caregivers' susceptibility and vulnerability to perceive the weight of the burden and finally result in decreased physical health.
Another reason might be that the employed caregivers could get the benefits of working when giving care to older adults, which was in agreement with previous study [31]. This finding sheds light on the effects of income and employment on caregiver' QOL.

Caregivers suffering from chronic diseases usually encountered numerous negative repercussions on both physical and mental health. The most likely reason was that their disease put them at a higher risk to lose physical strength and vitality. This subsequently resulted in decreased physical and mental health $[23,32,33]$. In China, most Chinese caregivers neglected their own health status [33], focusing more, if not completely, on the illness of the elderly. In this frame of mind they did not perceive the impacts of this placed on them, although the physical or mental evidence was present. Hence, the caregivers' physical and mental well being were decreased due to an increased risk of stress-related mortality.

The caregiver's relationship with the elderly was strongly related to caregivers' physical and mental health. In this study, adult children of the elderly accounted for the majority of the family caregiver (66.5\%). In China, it is an obligation to provide care for the elderly, owing to the Confucian thought of filial piety and the one-child policy. The adult children of the elderly take upon themselves heavy caring obligations. They have to sacrifice themselves to repay their parents [34], resulting in their physical and mental health being affected greatly.

In this study, we also found that living with the elderly was a significant predictor of physical QOL. The reason may be that, the caregivers living with the elderly, have to manage more stressful and difficult circumstance of caring, as well as spend more time and vigor undertaking the care tasks, which would compromise physical health.

Subjective Caregivers Burden held the most weight in interpretation of QOL, accounting for $12.1 \%$ and $17.3 \%$ of the observed variability in physical and mental QOL respectively. This is similar to Saunders' study which shows that Caregiver Burden explained most (62\%) of the variance in caregiver' HRQOL of the older patients with heart failure [35]. Caregivers experiencing heavier 
Table 2 QOL Scores in characteristics of the older adults and their caregivers and objective caring loads

\section{Caregivers' demographic characteristics}

PCS

\section{Gender}

Male

$74.09 \pm 17.10$

$65.59 \pm 15.98$

Female

$72.27 \pm 17.44$

$63.35 \pm 17.74^{*}$

Age (years old)

$\leq 40$

$74.17 \pm 16.12$

$63.85 \pm 16.46$

41-49

$72.52 \pm 15.88$

$63.54 \pm 16.01$

$\geq 50$

$71.89 \pm 20.47$

$65.83 \pm 19.17$

Marital status

Married

$72.87 \pm 17.46$

$64.51 \pm 17.19$

Others

$73.87 \pm 16.41$

$62.61 \pm 16.22$

Educational level

$<$ Senior middle school

$69.82 \pm 18.04^{* *}$

$62.41 \pm 16.92^{* *}$

$\geq$ Senior middle school

$75.61 \pm 16.22$

$65.62 \pm 17.04$

Monthly household income of caregivers(Yuan)

$<1000$

$65.70 \pm 18.29^{* *}$

$58.67 \pm 17.41^{* *}$

1000-1999

$72.40 \pm 18.98^{*}$

$64.13 \pm 17.41$

2000-2999

$73.13 \pm 16.95^{*}$

$63.96 \pm 16.84$

$\geq 3000$

$76.67 \pm 14.57$

$67.12 \pm 16.25$

Chronic diseases

No

$76.12 \pm 16.69^{* *}$

$65.84 \pm 16.61^{* *}$

Yes

$71.25 \pm 17.43$

$63.36 \pm 17.28$

Living with the elderly

Yes

$72.51 \pm 17.50$

$63.35 \pm 17.38$

No

$73.00 \pm 17.32$

$64.70 \pm 16.78$

Relationship to the patient

Spouse

$68.24 \pm 20.65^{* *}$

$62.38 \pm 18.14$

Daughter

$72.50 \pm 17.12$

$63.72 \pm 18.21$

Son

$75.70 \pm 15.75$

$65.99 \pm 16.01$

Daughter in law

$73.33 \pm 15.64$

$65.26 \pm 15.77$

Others

$71.87 \pm 18.47$

$63.33 \pm 17.01$

Caregiving in assistance for daily living

Not at all

$78.31 \pm 14.07$

$69.31 \pm 16.97$

Occasionally

$74.82 \pm 16.18^{*}$

$65.73 \pm 16.27^{* *}$

Frequently

$65.13 \pm 18.70^{* *}$

$57.71 \pm 16.54^{* * *}$

Always

$72.09 \pm 18.66^{*}$

$62.51 \pm 17.63^{*}$

Caregiving in assistance for housekeeping

Not at all

$77.83 \pm 14.77$

$70.16 \pm 16.65$

Occasionally

$76.31 \pm 15.79$

$66.44 \pm 16.35^{*}$

Frequently

$67.23 \pm 17.46^{* *}$

$60.24 \pm 16.44^{* *}$

Always

$70.55 \pm 19.40^{*}$

$60.93 \pm 18.11^{* *}$

Caregiving in assistance for transportation

Not at all

$77.41 \pm 15.84$

$69.30 \pm 17.55$

Occasionally

$73.09 \pm 16.52^{* *}$

$63.82 \pm 15.89^{* *}$ 
Table 2 QOL Scores in characteristics of the older adults and their caregivers and objective caring loads (Continued)

Frequently
Always
Not at all
Caregiving in assistance for health
Not at all
Occasionally
Frequently
Numbers of caregivers
1
2
3
$\geq 4$
Currently employed
no
yes
Time spent in caregiving everyday
$<4 \mathrm{~h}$
$5-6 \mathrm{~h}$
$7-8 \mathrm{~h}$
$9-24 \mathrm{~h}$

Time spent in caregiving everyday

Care duration (years)

$\leq 1$

$1-4$

$\geq 4$

The elderly' characteristics

\section{Gender}

Male

Female

Age

60-69

70-79

$\geq 80$

\section{Marital status}

Married

Others

\section{Educational level}

$<$ Junior middle school

zJunior middle school

Income level of the elderly(yuan)

$<1000$ 元
$1000-1999$
$2000-2999$
$\geq 3000$

$<1000$ 元

2000-2999

$\geq 3000$
$71.59 \pm 17.56^{* *}$

$70.58 \pm 19.34^{* *}$

$79.53 \pm 14.87$

$73.38 \pm 16.07^{*}$

$68.64 \pm 18.28^{* *}$

$71.73 \pm 19.58^{* *}$

$72.64 \pm 18.88$

$73.62 \pm 16.34$

$74.51 \pm 16.52$

$70.22 \pm 18.04^{*}$

$68.02 \pm 19.13^{* *}$

$75.31 \pm 15.96$

$75.72 \pm 16.13$

$66.06 \pm 17.01^{*}$

$68.97 \pm 18.60^{*}$

$63.67 \pm 19.28^{* *}$

$73.67 \pm 19.28^{*}$

$73.48 \pm 16.64$

$72.73 \pm 16.75$

$72.92 \pm 18.38$

$73.28 \pm 17.19$

$72.66 \pm 17.49$

$74.93 \pm 16.91$

$72.14 \pm 17.28^{*}$

$71.05 \pm 17.83^{* *}$

$73.96 \pm 17.47$

$71.71 \pm 17.07^{*}$

$72.35 \pm 17.25$

$73.67 \pm 17.32$

$70.30 \pm 17.69^{* *}$

$73.98 \pm 17.06^{*}$

$74.45 \pm 17.10$

$74.05 \pm 17.13$
$63.68 \pm 16.99 * *$

$60.96 \pm 18.41^{* *}$

$69.73 \pm 17.80$

$64.70 \pm 15.99^{*}$

$60.28 \pm 16.65^{* *}$

$62.81 \pm 18.36^{* *}$

$65.96 \pm 17.29$

$64.08 \pm 16.85$

$65.09 \pm 18.21$

$62.02 \pm 15.83$

$60.46 \pm 18.03^{* *}$

$65.94 \pm 16.32$

$66.64 \pm 16.29$

$57.88 \pm 16.22^{*}$

$60.78 \pm 16.54^{*}$

$55.00 \pm 20.33^{* *}$

$65.00 \pm 20.33^{*}$

$65.14 \pm 17.41$

$63.31 \pm 17.01$

$64.52 \pm 16.87$

$63.87 \pm 16.83$

$64.74 \pm 17.37$

$65.29 \pm 17.54$

$63.44 \pm 16.21$

$63.83 \pm 17.64$

$65.37 \pm 16.98$

$62.77 \pm 17.13^{*}$

$64.36 \pm 16.90$

$64.22 \pm 17.25$

$62.76 \pm 17.48$

$64.06 \pm 16.22$

$65.55 \pm 17.47$

$65.29 \pm 16.99$ 
Table 2 QOL Scores in characteristics of the older adults and their caregivers and objective caring loads (Continued)

Number of chronic diseases

\begin{tabular}{llr}
1.00 & $74.71 \pm 16.89$ & $65.80 \pm 16.75$ \\
2.00 & $72.52 \pm 16.50^{*}$ & $64.22 \pm 17.01$ \\
$\geq 3.00$ & $68.93 \pm 18.74^{* *}$ & $60.04 \pm 17.39^{* *}$ \\
ADL & & $67.95 \pm 16.60$ \\
$<26$ & $77.39 \pm 15.75$ & $61.46 \pm 16.90^{* *}$ \\
\hline 26 & $69.73 \pm 17.72^{* *}$ & 6 \\
\hline
\end{tabular}

${ }^{*} P<0.05$

${ }^{*} P<0.01$

Table 3 Hierarchical multiple regression predicting the PCS scores

\begin{tabular}{|c|c|c|c|c|c|c|c|}
\hline & $\begin{array}{l}\text { Estimate } \\
\text { (B) }\end{array}$ & $\begin{array}{l}\text { Standardized } \\
\text { estimate }(\beta)\end{array}$ & $\mathrm{t}$ & $P$ & $95 \% \mathrm{Cl}$ of $\beta$ & $\mathrm{R}^{2}$ & $\Delta \mathrm{R}^{2}$ \\
\hline Constant & 67.905 & & 8.191 & $<0.001$ & $51.636 \sim 84.174$ & & \\
\hline Block 1. The Elderly' Characteristics & & & & & & 0.034 & 0.034 \\
\hline Age & -0.075 & -0.037 & -1.124 & 0.261 & $-0.206 \sim 0.056$ & & \\
\hline Sex & -0.015 & 0.000 & -0.015 & 0.988 & $-2.005 \sim 1.975$ & & \\
\hline Educational level & -1.180 & -0.054 & -1.597 & 0.111 & $-2.630 \sim 0.270$ & & \\
\hline Marital status & 0.230 & 0.021 & 0.679 & 0.498 & $-0.436 \sim 0.896$ & & \\
\hline Income level & 0.256 & 0.016 & 0.431 & 0.667 & $-0.910 \sim 1.422$ & & \\
\hline Number of chronic diseases & -0.438 & -0.022 & -0.718 & 0.473 & $-1.636 \sim 0.760$ & & \\
\hline$A D L$ & 0.112 & 0.081 & 1.980 & 0.048 & $0.001 \sim 0.223$ & & \\
\hline Block 2. Caregivers' Demographic Characteristics & & & & & & 0.103 & 0.069 \\
\hline Age & 0.030 & 0.019 & 0.549 & 0.583 & $-0.078 \sim 0.139$ & & \\
\hline Sex & 0.594 & 0.017 & 0.573 & 0.567 & $-1.441 \sim 2.629$ & & \\
\hline $\begin{array}{l}\text { Educational level (<senior middle school=0; } \geq \text { senior middle } \\
\text { school=1) }\end{array}$ & 1.036 & 0.063 & 1.641 & 0.101 & $-0.203 \sim 2.275$ & & \\
\hline Monthly household income of caregivers & 1.685 & 0.101 & 2.662 & 0.008 & $0.443 \sim 2.927$ & & \\
\hline Marital status (married=1;others $=0$ ) & -0.419 & -0.026 & -0.888 & 0.375 & $-1.345 \sim 0.507$ & & \\
\hline Chronic disease (yes $=1 ;$ no $=0$ ) & -3.747 & -0.103 & -3.428 & 0.001 & $\begin{array}{l}-5.892 \sim \\
-1.602\end{array}$ & & \\
\hline Relationship to the patient & 1.186 & 0.150 & 4.556 & $<0.001$ & $0.675 \sim 1.697$ & & \\
\hline Currently employed (yes $=1 ; \mathrm{no}=0$ ) & 3.279 & 0.087 & 2.454 & 0.014 & $0.657 \sim 5.901$ & & \\
\hline Living with the elderly (yes $=1 ;$ no $=0$ ) & -2.294 & -0.066 & -2.202 & 0.028 & $\begin{array}{l}-4.338 \sim \\
-0.249\end{array}$ & & \\
\hline Block 3. Objective Caregiving Loads & & & & & & 0.129 & 0.026 \\
\hline Caregiving in assistance for daily living & -1.130 & -0.060 & -1.154 & 0.249 & $-3.053 \sim 0.792$ & & \\
\hline Caregiving in assistance for housekeeping & -1.051 & -0.055 & -1.193 & 0.233 & $-2.779 \sim 0.678$ & & \\
\hline Caregiving in assistance for transportation & 0.967 & 0.054 & 1.269 & 0.205 & $-0.529 \sim 2.464$ & & \\
\hline Caregiving in assistance for health care & -0.078 & -0.004 & -0.086 & 0.931 & $-1.844 \sim 1.689$ & & \\
\hline Numbers of caregivers & -0.695 & -0.097 & -3.202 & 0.001 & $\begin{array}{l}-1.121 \sim \\
-0.269\end{array}$ & & \\
\hline Time spent in caregiving everyday & -0.614 & -0.044 & -1.238 & 0.216 & $-1.587 \sim 0.359$ & & \\
\hline Care duration & -0.007 & -0.022 & -0.727 & 0.468 & $-0.025 \sim 0.012$ & & \\
\hline Block 4. Subjective Caregiver Burden & -0.428 & -0.364 & -12.049 & $<0.001$ & $\begin{array}{l}-0.497 \sim \\
-0.358\end{array}$ & 0.251 & 0.121 \\
\hline Block5. SOC & 0.227 & 0.072 & 2.526 & 0.012 & $0.051 \sim 0.403$ & 0.255 & 0.004 \\
\hline
\end{tabular}


Table 4 Hierarchical multiple regression predicting the MCS scores

\begin{tabular}{|c|c|c|c|c|c|c|c|}
\hline & $\begin{array}{l}\text { Estimate } \\
\text { (B) }\end{array}$ & $\begin{array}{l}\text { Standardized estimate } \\
(\beta)\end{array}$ & $\mathrm{t}$ & $P$ & $95 \% \mathrm{Cl}$ of $\beta$ & $\mathrm{R}^{2}$ & $\triangle \mathrm{R}^{2}$ \\
\hline Constant & 45.489 & & 5.713 & $<0.001$ & 29.863 61.115 & & \\
\hline Block 1. The Elderly' Characteristics & & & & & & 0.031 & 0.031 \\
\hline Age & -0.015 & -0.007 & -0.231 & 0.817 & $-0.141 \sim 0.111$ & & \\
\hline Sex & 1.449 & 0.042 & 1.488 & 0.137 & $-0.462 \sim 3.360$ & & \\
\hline Educational level & -0.507 & -0.024 & -0.715 & 0.475 & $-1.901 \sim 0.886$ & & \\
\hline Marital status & -0.008 & -0.001 & -0.024 & 0.981 & $-0.648 \sim 0.633$ & & \\
\hline Income & 0.294 & 0.018 & 0.515 & 0.607 & $-0.827 \sim 1.415$ & & \\
\hline Number of chronic disease & -0.196 & -0.010 & -0.333 & 0.740 & $-1.350 \sim 0.958$ & & \\
\hline$A D L$ & 0.102 & 0.075 & 1.851 & 0.065 & $-0.006 \sim 0.210$ & & \\
\hline Block 2.Caregivers' Demographic Characteristics & & & & & & 0.072 & 0.041 \\
\hline Age & 0.130 & 0.085 & 2.440 & 0.015 & $0.025 \sim 0.234$ & & \\
\hline Sex & -0.865 & -0.025 & -0.870 & 0.385 & $-2.817 \sim 1.087$ & & \\
\hline $\begin{array}{l}\text { Educational level ( }<\text { senior middle school }=0 \text {; } \geq \text { senior middle } \\
\text { school }=1 \text { ) }\end{array}$ & 0.851 & 0.053 & 1.403 & 0.161 & $-0.339 \sim 2.040$ & & \\
\hline Monthly household income & 1.214 & 0.074 & 2.004 & 0.045 & $0.025 \sim 2.403$ & & \\
\hline Marital status(married=1;others=0) & -0.567 & -0.035 & -1.252 & 0.211 & $-1.455 \sim 0.321$ & & \\
\hline Chronic disease (yes $=1 ;$ no $=0$ ) & -2.459 & -0.070 & -2.107 & 0.035 & $-4.749 \sim 0.169$ & & \\
\hline Relationship to the patient & 1.027 & 0.133 & 4.107 & $<0.001$ & $0.536 \sim 1.517$ & & \\
\hline Currently employed (yes $=1 ; \mathrm{no}=0$ ) & 0.960 & 0.026 & 0.749 & 0.454 & $-1.556 \sim 3.476$ & & \\
\hline Living with the elderly (yes $=1 ; \mathrm{no}=0$ ) & -0.753 & -0.022 & -0.753 & 0.452 & $-2.717 \sim 1.211$ & & \\
\hline Block 3. Objective Caregiving Loads & & & & & & 0.094 & 0.022 \\
\hline Caregiving in assistance for daily living & -1.072 & -0.058 & -1.141 & 0.254 & $-2.916 \sim 0.772$ & & \\
\hline Caregiving in assistance for housekeeping & -1.262 & -0.068 & -1.493 & 0.136 & $-2.922 \sim 0.397$ & & \\
\hline Caregiving in assistance for transportation & 0.307 & 0.017 & 0.421 & 0.674 & $-1.126 \sim 1.741$ & & \\
\hline Caregiving in assistance for health care & 0.704 & 0.038 & 0.814 & 0.416 & $-0.993 \sim 2.402$ & & \\
\hline Numbers of caregivers & -0.390 & -0.055 & -1.866 & 0.062 & $-0.800 \sim 0.020$ & & \\
\hline Time spent in caregiving everyday & -0.895 & -0.066 & -1.884 & 0.060 & $-1.828 \sim 0.037$ & & \\
\hline Care duration & 0.000 & -0.001 & -0.047 & 0.963 & $-0.018 \sim 0.017$ & & \\
\hline Block 4. Subjective Caregiver Burden & -0.490 & -0.427 & -14.388 & $<0.001$ & $\begin{array}{l}-0.557 \sim \\
-0.423\end{array}$ & 0.266 & 0.173 \\
\hline Block5. SOC & 0.397 & 0.129 & 4.597 & $<0.001$ & $0.227 \sim 0.566$ & 0.282 & 0.016 \\
\hline
\end{tabular}

burden, reported lower levels of both physical and mental QOL. Assuming the responsibility of caring for the elderly may result in significant disturbances on the caregivers' time. This makes it difficult to find spare time away from their caregiving obligation to relax or attend social activities and relieve themselves. Caring for an ill family member may actually result in an imbalance between personal affairs and family function. Subjective Caregivers Burden compromises both the physical and mental health status of the caregivers, resulting in an increased risk of stress-related diseases. Caregivers, who view the elderly illness as problematic or consider treatment to be stressful, feel more uncertain and hopeless. They are also much more likely to appraise the caring responsibilities negatively and tend to be emotionally distressed and show physical symptoms. Personal subjective appraisal of the same stressors may be different owing to the caregivers' abilities to self-regulate and cope. Subjective consciousness always determines psychological discomfort by determining whether the caregiver perceives the burden. As is consistent with other studies, it has been deduced that QOL in caregivers is closely associated with the caregiver's subjective perception of the impact of caring for the elderly [36,37].

In this study, SOC was moderately and positively associated with both physical and mental health, which was consistent with previous studies [38,39]. It was found that caregivers with high SOC scores enjoyed high 
physical and mental QOL. Caregivers with a higher SOC, when providing caregiving to the elderly, could choose the adaptive coping response and mobilize resources to handle the difficult caring circumstances. SOC could help the caregivers feel more confident in dealing with the care tasks, improving their abilities to confront stressors. SOC is an orientation to life that can help caregivers avert emotional discomforts in stressful situations and protect both mental and physical health. The caregivers with high SOC consider stressors to be more predictable, and view the stressors as worthwhile and meaningful during the caring process [40].

It is highly recommended that health care resources for the elderly, supporting their caregivers be optimized, especially by delivering psychological counseling services. Targeted support for the most burdened caregivers, such as skills training to aid in alleviating burden and adaptive coping strategies should also be provided.

The present study bears the limitations that it is characterized by cross-sectional research, therefore one cannot derive any conclusions on the causality of the associations observed between caregiving burden and QOL. Moreover, variables related to nurses who could give assistance to caregivers in the communities were not considered because currently in China there are no nurses who assist caregivers in the caregiver role in the home setting. Finally, caregivers were selected by convenience sampling, which may limit the generalizability of this study to other populations. However, despite the above limitations, this study has notable strong points. Firstly, the sample size was quite large. Secondly, there was a high response rate, most likely due to the fact that face to face interviews allowed for more collection of information. Finally, 15 communities in 3 eastern cities (Shenyang, Yantai and Nanqiao of Shanghai) of China were selected. These cities are located at the north, central and south of eastern China. These three cities contain large elderly populations. Thus, this could represent the care situation of most eastern areas of China.

\section{Conclusions}

Most Chinese caregivers of the elderly experienced low levels of HRQOL. Mental QOL were disrupted more seriously than physical QOL. A decrease in caregiver burden ought to promote better management of caregiving tasks, and improve QOL. Also, coping capability, like SOC, are needed to decrease the impact of caregiving on HRQOL of Chinese caregivers.

\footnotetext{
Abbreviations

QOL: Quality of Life; HRQOL: Health Related Quality of Life; SF-36: the 36-item Short-Form Health Survey; PCS: Physical Component Summary; MCS: Mental Component Summary; ZBI: the Zarit Caregiver Burden Interview; SOC: Sense of Coherence; HMR: Hierarchical Multiple Regression analysis.
}

\section{Competing interests}

The authors declare that they have no competing interests.

\section{Authors' contributions}

$X Y$ the data collection, statistical analysis and drafting and revision of the manuscript. YH contributed to interpretation and collection of the data, SMG contributed to the data collection and revision of the manuscript. LW was responsible for the development, design. All authors read and approved the final manuscript.

\section{Acknowledgements}

The authors thank Siew Tzuh Tang who provided the scales of Chinese edition of SOC.

Received: 29 August 2012 Accepted: 16 November 2012

Published: 27 November 2012

\section{Reference}

1. Zheng XY, Chen LX: Features of China's population ageing and its policies. Chin Gen Pract 2006, 9:1919-1923.

2. Amendola F, Oliveira MA, Alvarenga MR: Influence of social support on the quality of life of family caregivers while caring for people with dependence. Rev ESC Enferm USP 2011, 45(4):884-9.

3. Martinez-Martin P, Rodriguez-Blazquez C, Forjaz MJ: Quality of life and burden in caregivers for patients with Parkinson's disease: concepts, assessment and related factors. Expert Rev Pharmacoecon Outcomes Res 2012, 12(2):221-30.

4. Juratovac E, Morris DL, Zauszniewski JA, Wykle ML: Effort, workload, and depressive symptoms in family caregivers of older adults: conceptualizing and testing a work-health relationship. Res Theory Nurs Pract 2012, 26(2):74-94.

5. Schulz R, Beach SR: Caregiving as a risk factor for mortality: the Caregiver health effects study. J Am Med Assoc 1999, 282(23):2215-2219.

6. Song Jl, Shin DW, Choi JY, Kang J, Baik YJ, Mo H, Park MH, et al: Quality of life and mental health in family caregivers of patients with terminal cancer. Support Care Cancer 2011, 19(10):1519-26.

7. Northouse LL, Mood D, Kershaw T, Schafenacker A, Mellon S, Walker J, Galvin $\mathrm{E}$, et al: Quality of life of women with recurrent breast cancer and their family members. J Clin Oncol 2002, 20:4050-64.

8. Rhee YS, Yun YH, Park S, Shin DO, Lee KM, Yoo HJ, Kim JH, et al: Depression in family caregivers of the elderly: the feeling of burden as a predictor of depression. J Clin Oncol 2008, 26:5890-5.

9. Wilkinson AM, Joanne Lynn: Caregiving for advanced chronic illness patients. Tech region Anesth Pain Manag 2005, 9:122-132.

10. Julkunen J, Ahlström R: Hostility, anger, and sense of coherence as predictors of health-related quality of life. Results of an ASCOT substudy. J Psychosom Res 2006, 61(1):33-9.

11. Chumbler NR, Rittman MR, Wu SS: Associations in sense of coherence and depression in caregivers of stroke survivors across 2 years. J Behav Health Serv Res 2008, 35(2):226-34.

12. Antonovsky A: Unraveling the mystery of health: how people manage stress and stay well. San Francisco: Jossey-Bass; 1987.

13. Mei'e X: The related topics of long-term care for the elderly [M]. Taipei: Laureate Book Co., Ltd; 1993:14-26.

14. Ni R, Liu X, Zhu C: Digital Health Management of long-term cared disabled elders in urban communities. Health Research 2011, 5:352-354. In Chinese.

15. Ware JE Jr, Kosinski M, Gandek B, Aaronson NK, Apolone G, Bech P, et al: The factor structure of the SF-36 Health Survey in 10 countries: results from the IQOLA Project. International Quality of Life Assessment. J Clin Epidemiol 1998, 51:1159-65.

16. Li L, Wang HM, hen YS: Chinese SF-36 health survey: translation, culture adaption, validation, and normalisation. J Epidemiol Community Health 2003, 57(4):259-263.

17. Lawton MP, Brody EM: Assessment of older people: self-maintaining and instrumental activities of daily living. Gerontologist 1969, 9(3):179-86.

18. Emanuel EJ, Fairclough DL, Slutsman J, Alpert H, Baldwin D, Emanuel LL: Assistance from family members, friends, paid care givers and volunteers in the care of terminally ill patients. New Engl J Med 1999, 341:956-963. 
19. Zarit SH, Femia EE, Kim K, Whitlatch CJ: The structure of risk factors and outcomes for family caregivers: implications for assessment and treatment. Aging Ment Health 2010, 14(2):220-31.

20. Lu L, Wang L, Yang X, Feng Q: Zarit Caregiver Burden Interview: Development, reliability and validity of the Chinese version. Psy Clin Neuros 2009, 63:730-734

21. Eriksson M, Lindström B: Validity of Antonovsky's sense of coherence scale: a systematic review. J Epidemiol Community Health 2005, 59:460-6.

22. 20Kahn HA, Sempos CT: Statistical methods in epidemiology. New York: Oxford University Press; 1989:147-8. 156-7.

23. Tzuh Tang S, Li CY: The important role of sense of coherence in relation to depressive symptoms for Taiwanese family caregivers of cancer patients at the end of life. J Psychosom Res 2008, 64(2):195-203.

24. Ningxiu L, Chaojie L, Jun L, Xiaohui R: The norms of SF-36 scale scores in urban and rural residents of Sichuan province. J West China University Med Sci 2001, 32(1):43-47.

25. Ho SC, Chan A, Woo J, Chong P, Sham A: Impact of caregiving on health and quality of life: a comparative population-based study of caregivers for elderly persons and noncaregivers. J Gerontol A Biol Sci Med Sci 2009, 64(8):873-9.

26. McPherson CJ, Wilson KG, Chyurlia L, Leclerc C: The caregiving relationship and quality of life among partners of stroke survivors: a cross-sectional study. Health Qual Life Outcomes 2011, 9(1):29.

27. Saunders MM: Factors associated with caregiver burden in heart failure family caregivers. West J Nurs Res 2008, 30(8):943-59.

28. Van Puymbroeck M, Rittman MR: Quality-of-life predictors for caregivers at 1 and 6 months poststroke: Results of path analyses. J Rehabi Rese Develop 2005, 42(6):747-60.

29. Martínez-Martín P, Benito-León J, Alonso F, Catalán MJ, Pondal M, Zamarbide I, Tobías A, de Pedro J: Quality of life of caregivers in Parkinson's disease. Qual Life Res 2005, 14(2):463-72.

30. Haley WE, Roth DL, Coleton MI, Ford GR, West CA, Collins RP, Isobe TL: Appraisal, coping, and social support as mediators of well-being in black and white family caregivers of patients with Alzheimer's disease. J Consult Clin Psychol 1996, 64(1):121-9.

31. Saunders MM: Working and caregiving: a comparison of employed and unemployed caregivers of older heart failure patients. Holist Nurs Pract 2010, 24(1):16-22.

32. Morimoto T, Schreiner AS, Asano H: Caregiver burden and health-related quality of life among Japanese stroke caregivers. Age Ageing 2003, 32:218-223.

33. Yang X, Wang L, He J, Ge C, Chang Y, Fu J, Wei J, Pattaramongkolar E, Zhou $Y$ : Factors related to depressive symptoms among Chinese caregivers of cancer patients. Psychooncology 2012, 21(10):1063-70.

34. Tsai HH, Chen MH, Tsai YF: Perceptions of filial piety among Taiwanese university students. J Adv Nurs 2008, 63(3):284-90

35. Saunders MM: Indicators of health-related quality of life in heart failure family caregivers. J Community Health Nurs 2009, 26(4):173-82.

36. 29Chang HY, Chiou CJ, Chen NS: Impact of mental health and caregiver burden on family caregivers' physical health. Arch Gerontol Geriat 2010, 50(3):267-71.

37. 30Takai M, Takahashi M, Iwamitsu Y, Oishi S, Miyaoka H: Subjective experiences of family caregivers of patients with dementia as predictive factors of quality of life. Psychogeriatrics 2011, 11(2):98-104.

38. 31Mizuno E, Iwasaki M, Sakai I, Kamizawa N: Sense of coherence and quality of life in family caregivers of persons with schizophrenia living in the community. Arch Psychiatr Nurs 2012, 26(4):295-306.

39. 32Khanjari S, Oskouie F, Langius-Eklöf A: Lower sense of coherence, negative religious coping, and disease severity as indicators of a decrease in quality of life in Iranian family caregivers of relatives with breast cancer during the first 6 months after diagnosis. Cancer Nurs 2012, 35(2):148-56.

40. 33Chumbler NR, Rittman M, Van Puymbroeck M, et al: The sense of coherence, burden, and depressive symptoms in informal caregivers during the first month after stroke. Int J Geriatr Psych 2004, 19(10):944-953.

\section{Submit your next manuscript to BioMed Central and take full advantage of:}

- Convenient online submission

- Thorough peer review

- No space constraints or color figure charges

- Immediate publication on acceptance

- Inclusion in PubMed, CAS, Scopus and Google Scholar

- Research which is freely available for redistribution 